\title{
Spatial Characteristics of House Unit and Role of Shared Chan at Chitlada State Railway of Thailand Housing Site in Bangkok
}

\author{
Mari Tanaka ${ }^{1}$, Yukiyo Kikuchi ${ }^{2}$ and Shuji Funo ${ }^{3}$ \\ ${ }^{1}$ Associate Professor, Faculty of Education, Gunma University, Japan \\ ${ }^{2}$ M. D. Associates, Japan \\ ${ }^{3}$ Associate Professor, Department of Architecture and Environmental Design, Kyoto University, Japan
}

\begin{abstract}
The purpose of this study is to evaluate and analyze the house unit planning at Chitlada State Railway of Thailand (SRT) housing site in Bangkok. Row houses at Chitlada were made of timber and were built on concrete pillars and had multipurpose space such as a Taithun (underneath) and a Chan (terrace) which were often seen at traditional Thai houses. In this paper, we discuss about the use of house unit and its relationship with the shared Chan. We found that the use of house unit shows the demarcation of sleeping space and multipurpose connecting space. The shared Chan is not actively used for daily social communications as used to be, however still helped for practical uses such as work space, housework, storage, passage and as ritual space. In addition spatial perception of Chan as multipurpose connecting space can be shared among residents. The shared Chan supports the residents' continuous living and indicated its importance in house unit planning which reflects the Thai way of life.
\end{abstract}

Keywords: Bangkok; use of house unit; multipurpose common space; house unit planning

\section{Introduction}

The State Railway of Thailand (SRT) housing is a kind of welfare housing provided by the government to the railway employees ${ }^{1}$. The Chitlada housing site, one of the SRT Housing, was built more than 60 years ago and still exists ${ }^{2}$ (Fig.1, Fig. 2). In Chitlada there are detached houses, duplex houses and row houses. All of them were built on 2-2.5m high concrete pillars, and leave the area underneath the house ('Thaithun' in Thai) available for multipurpose uses. The kitchen was separated from the main building by terrace ('Chan' in Thai). The roof has long eaves and an appropriate slope. These old timber houses have a unique design and reflect the traditional way of life that is rare in present day Bangkok.

Concerning the SRT, Suehiro ${ }^{3}$ and Kakizaki ${ }^{4}$ are looking at the SRT industry from the socioeconomic point of view to explain the development of railway industry. Pimonsathean ${ }^{5}$ selected 3 SRT housing sites where old timber houses are still existing, and appealed for conservation awareness. These researches are useful to understand the background and history of the SRT housing. Furthermore transition of housing sites, especially outstanding multipurpose space such as Taithun and Chan

Contact Author: Mari Tanaka, Associate Professor, Faculty of Education, Gunma University

Aramaki-machi, Maebashi, 371-8510 Japan

Tel: +81-27-220-7343 Fax: +81-27-220-7343

e-mai:mari@edu.gunma-u.ac.jp

(Received May 8, 2002; accepted August 26, 2002) at Chitlada, were described by Tanaka ${ }^{6}$. The Taithun was converted into private rooms or used for commercial activities. However the Chan on the contrary has undergone minor modifications.

This paper tries to understand the spatial characteristics of house unit with shared Chan by looking at the use of house unit. In addition, the role of the shared Chan is discussed. A house unit with a shared Chan is one of the outstanding housing design in Thailand. The similar house unit design with communal hall was built in neighboring country ${ }^{7}$. Understanding the role of shared Chan in Thai context is therefore important for future house unit planning.

\section{Methods}

The study gathered both primary and secondary data. Primary data was collected through a field survey on February and July 2001. Field surveys include interviews to community leaders, elderly people and residents. Referring to house unit space, residents were asked to indicate the place for basic activities such as sleeping, eating, communicating with people and relaxation including special occasions. Land use and physical measurements of the typical housing unit and observations were also conducted ${ }^{8}$. There are four types of row houses in Chitlada and row house RH6 has the shared Chan (Fig.3). Analyses focus on this type ${ }^{9}$. Secondary data was obtained at King Mongkut's Institute of Technology Ladkrabang and Silpakorn University among some literature that discusses about Thai houses. 


\section{The Use of House Units with Shared Chan 3-1 Shared Chan}

There are three common spaces such as the Chan and Chalieng A and Chalieng B in the RH6 (Fig.3). Activities and commodities placed on these space were analyzed before ${ }^{10}$. The spatial characteristics of theses space are summarized here.

Residents still keep Chan as a common space except 1 building ${ }^{11}$ (Fig.4). The Chan has 5 functions such as 1) work space: Residents who produces trousers place a sewing machine and working tables in this space. A housewife doing piecework by washing and ironing clothes inside the community also uses this space. 2) housework space: Residents use this space for preparing food, drying and washing clothes by using a washing machine. 3) storage space: There are lots of daily commodities related to washing and cooking kept here. 4) passage: It is a passage to access each of the room. Children are playing or running around. 5) ritual space: The Chan is still used for ceremonies such as inviting monks to bring happiness and for funeral ceremonies. Monks are usually invited to the Chan and to the outside special stage made by the residents. Residents still call this space 'Chan'.

\section{3-2 Shared Chalieng ${ }^{12}$}

Chalieng A is surrounded by three units including the original leader's unit. In about half of the cases the Chalieng A is used exclusively by certain families who live in adjacent units (6/13 building). A TVset, a sofa, a calendar are the commodities being placed at Chalieng A but not at Chan. Chalieng A is recognized and used as extension of private space.

Chalieng B is more of a closed space between two units. Originally the Chan and the Chalieng B were connected but in none of these buildings have this circular passage anymore. Chalieng B is used as a private space like Chalieng A (No. 80, 88, 92, 104). Furthermore house units connected with Chalieng B are used as rental rooms $^{13}$ (No. 94, 96, 100, 106, 108).
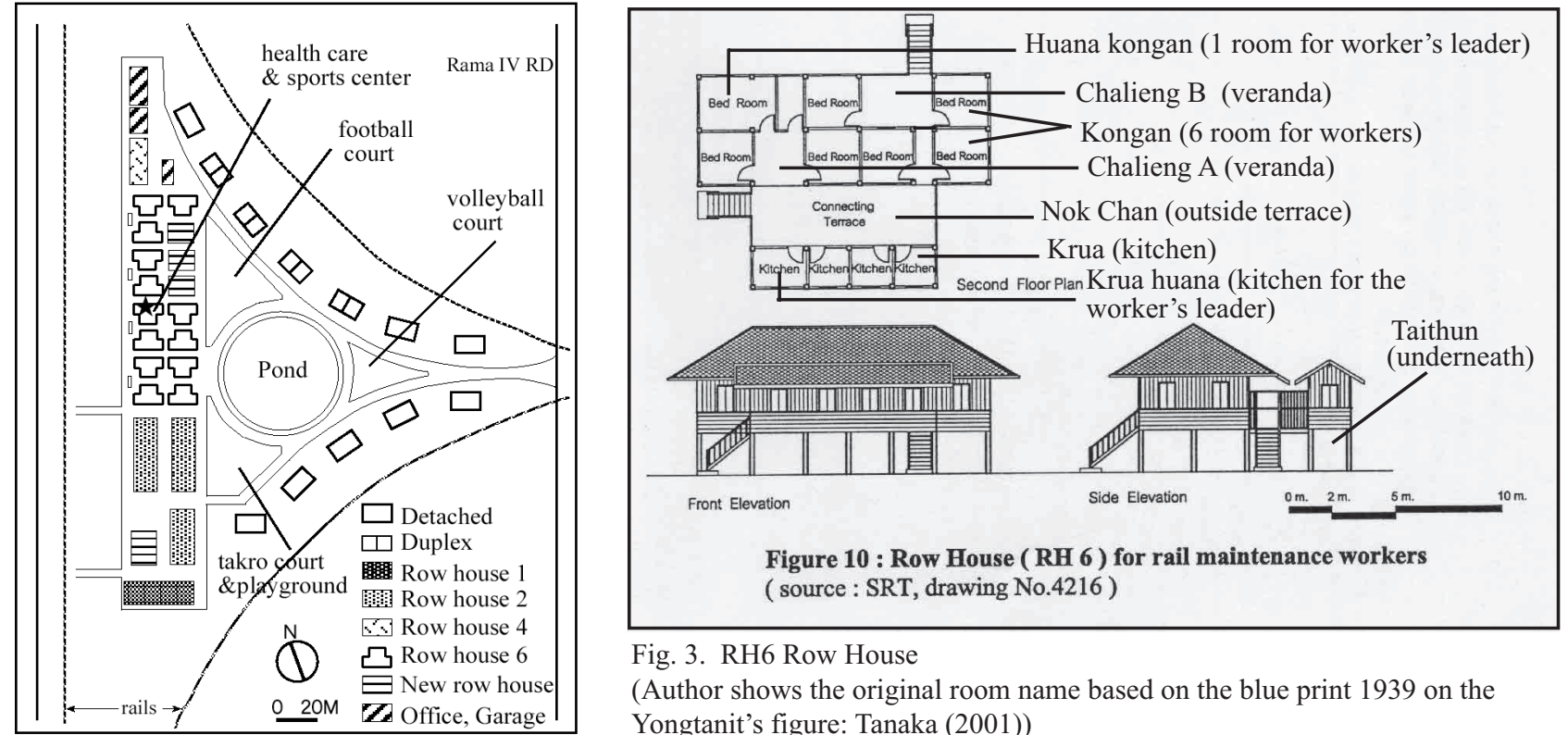

Fig. 3. RH6 Row House

(Author shows the original room name based on the blue print 1939 on the Yongtanit's figure: Tanaka (2001))

Fig. 1. Existing Conditions of Chitlada Housing Site 2001

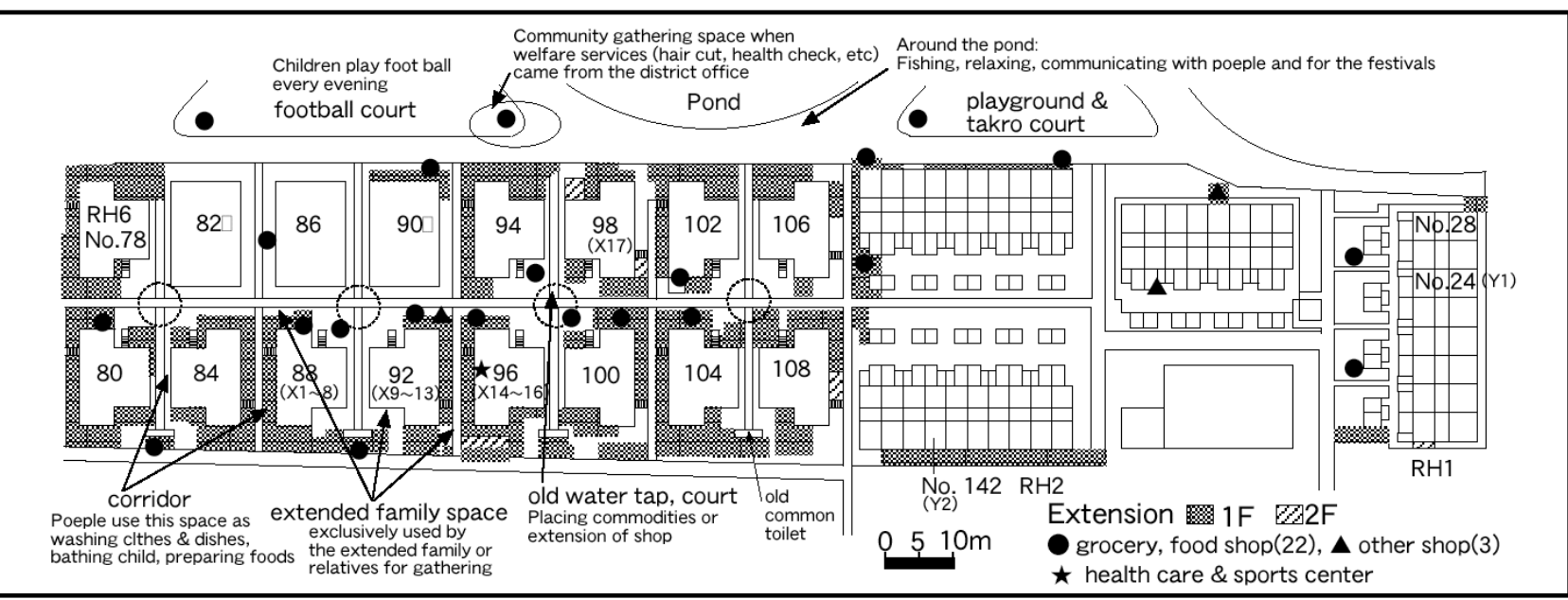

Fig. 2. Land Use 
Both Chalieng A and B are not called 'Chalieng' but 'Rabiang' nor are they given any other specific name by the residents. Residents distinguished this space from the Chan though ${ }^{14}$.

\section{3-3 The House Unit Size and Living Style}

Residents extended their living space according to their needs and now floor area of the unit varies ${ }^{15}$ (Table 1). In addition, residents extended their living space by four ways such as 1) including adjacent house unit or Chalieng or other space on the same floor , 2) using the unit upstairs and downstairs of the same building , 3) using the several house units inside the community, and 4) using the outdoor space as family gathering space. However residents do not extend their living space by putting walls on the shared Chan. There is only one building out of 13 buildings that shared Chan is gone to give way to an individual household (Fig.5).

There are several cases including adjacent units. X8 is extended living space by including the units and a part of shared Chan (Fig.5) . X4 and X5 are brother and sister and living next to each other. Using the unit upstairs and downstairs are more frequently seen. Parents live downstairs and the child's family lives upstairs (X1-X7, $\mathrm{X} 2-\mathrm{X} 6, \mathrm{X} 14-\mathrm{X} 15$ and $\mathrm{Y} 2$ ) or relatives live downstairs (X9-X11). This is because the downstairs space belongs to the residents who have the right to stay in the units upstairs even though there is no official rule. There are a number of residents working for SRT for generations. Therefore it is not rare to find persons who were born in Chitlada, grew up in Chitlada and have their own family in Chitlada. Relatives are also living in the house units inside the community. These people sometimes make their own gathering space outside by themselves. This family space is made by extending the house unit or utilizing the backside of the buildings and trees (Fig.2, Fig. 4).

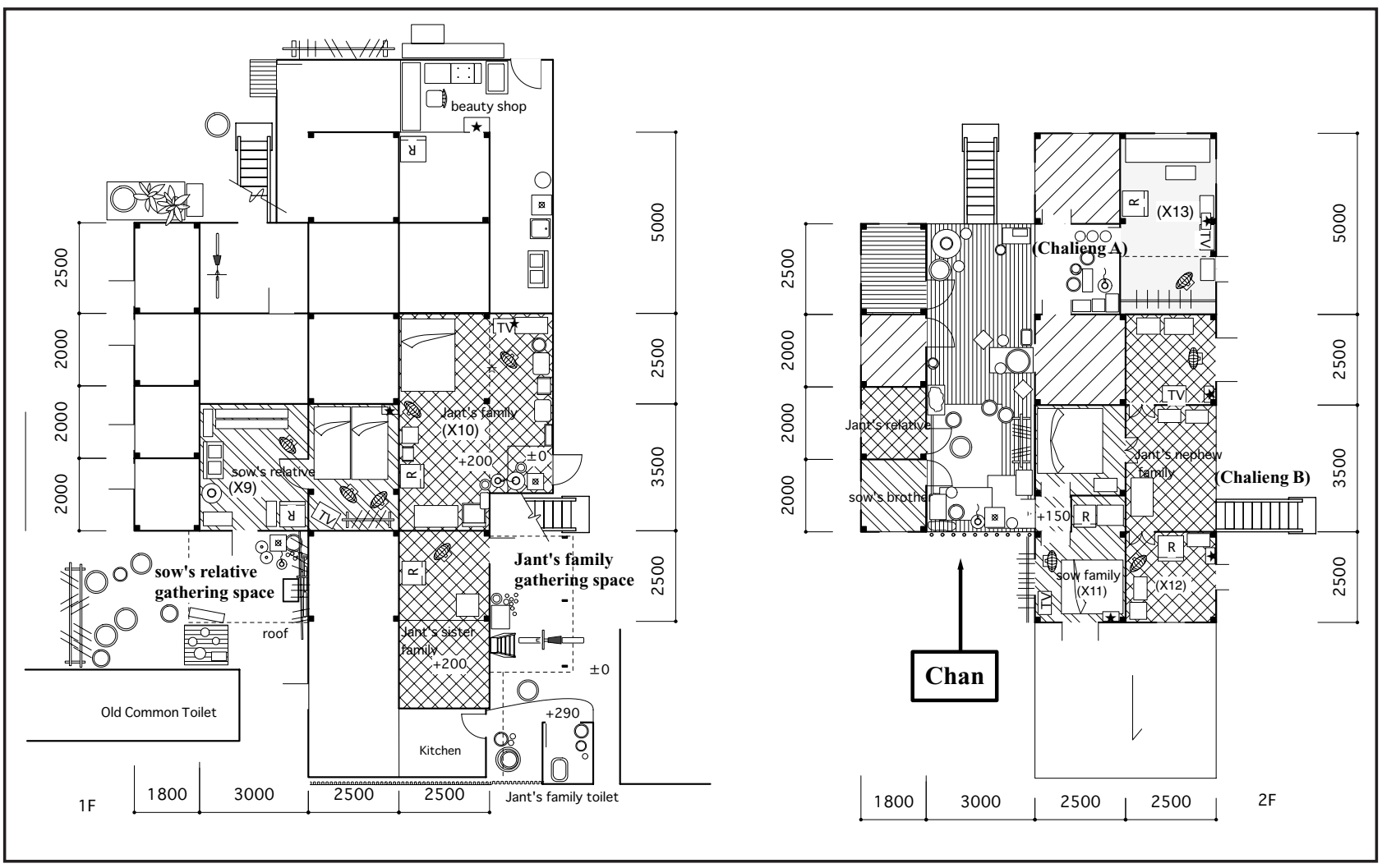

Fig. 4. RH6 No. 92 Building (Shared Chan, family gathering space, use of house units)

Table 1. Resindet's Profile

\begin{tabular}{|c|c|c|c|c|c|c|c|c|c|c|c|c|c|c|c|c|c|c|c|c|}
\hline & $\mathrm{X} 1$ & $x 2$ & X3 & X4 & X5 & $x 6$ & X7 & X8 & X9 & $\mathrm{X} 10$ & $\mathrm{X} 11$ & $\mathrm{X} 12$ & $\mathrm{X} 13$ & $\mathrm{X} 14$ & X15 & $\mathrm{X} 16$ & $\mathrm{X} 17$ & Y1 & Y2 & $\mathrm{Z1}$ \\
\hline Age of Family Head (yr.) & 54 & 42 & 48 & 35 & 38 & 23 & 31 & 53 & 40 & 52 & 48 & 39 & 46 & 53 & 36 & 28 & 53 & 51 & 30 & 48 \\
\hline Household ${ }^{* 1}$ & W & HW & HW & HWC & EXT & HWC & HWC & EXT & HWC & HW & $\mathrm{HC}$ & HWC & WC & EXT & W & WHC & HW & HW & EXT & HWC \\
\hline Household Size (person) & 1 & 2 & 2 & 4 & 3 & 4 & 3 & 5 & 3 & 2 & 3 & 3 & 3 & 3 & 1 & 3 & 2 & 2 & 6 & 3 \\
\hline Period of Stay in Chitlada (yr.) & 36 & 20 & 20 & 34 & 38 & 20 & 31 & 13 & 10 & 50 & 20 & N.A & N.A & 30 & 30 & N.A & 33 & 16 & 30 & 29 \\
\hline Period of Stay at Unit (yr.) & 31 & 5 & 5 & 16 & 16 & 5 & 31 & 13 & 10 & 25 & 20 & N.A & N.A & N.A & 30 & N.A & 33 & 16 & 2 & 29 \\
\hline Building Type & $\mathrm{RH} 6$ & RH6 & $\mathrm{RH} 6$ & RH6 & RH6 & RH6 & RH6 & RH6 & RH6 & $\mathrm{RH} 6$ & RH6 & RH6 & RH6 & RH6 & RH6 & RH6 & RH6 & RH1 & RH2 & $\mathrm{RH} 4$ \\
\hline Floor Level $(1 \mathrm{~F}, 2 \mathrm{~F})$ & $1 \mathrm{~F}$ & $1 \mathrm{~F}$ & $1 \mathrm{~F}$ & $1 \mathrm{~F}$ & $1 \mathrm{~F}$ & $2 \mathrm{~F}$ & $2 \mathrm{~F}$ & $2 \mathrm{~F}$ & $1 \mathrm{~F}$ & $1 \mathrm{~F}$ & $2 \mathrm{~F}$ & $2 \mathrm{~F}$ & $2 \mathrm{~F}$ & $1 \mathrm{~F}$ & $2 \mathrm{~F}$ & $2 \mathrm{~F}$ & $2 \mathrm{~F}$ & $1,2 \mathrm{~F}$ & $1,2 \mathrm{~F}$ & $1,2 \mathrm{~F}$ \\
\hline Floor Area ${ }^{{ }^{2}}$ (Sq.m) & 15.8 & 12.5 & 15.9 & 28.4 & 36.0 & 6.25 & 30 & 46.6 & 19.3 & 21.8 & 15.0 & 21.3 & 12.5 & 23.7 & 6.25 & 12.5 & 12.5 & 45.0 & 33.0 & 36.0 \\
\hline Unit Type $\star^{3}$ & 2 & 3 & 2 & 3 & 3 & 1 & 3 & 3 & 3 & 2 & 1 & 1 & 2 & 2 & 1 & 2 & 2 & 3 & 3 & 3 \\
\hline Source: Field & $\begin{array}{l}* 1: \\
\star 2 \\
* 3\end{array}$ & & & & & & & & & & & & & & & & & & & \\
\hline
\end{tabular}




\section{3-4 Demarcation of Sleeping Space}

People who live in the house unit were interviewed and observed while using the places for basic activities such as sleeping, eating, relaxing and communicating with people. Units are categorized into three types (Fig. 6). There are 4 cases of Type 1, which include all activities in one space. Half of these cases have bed inside the units. These units function more as a private sleeping space $(\mathrm{X} 6, \mathrm{X} 11)$. There are 7 cases of Type 2 having demarcation between sleeping space from others by furniture, floor mats or floor levels. They put a bed or place a shelf between sleeping space and others (X3, X17 and $\mathrm{X} 10)$. Utilizing lower ceiling and higher floor levels (X1, $\mathrm{X} 10, \mathrm{X} 14)$ are observed only in house unit at the 1st floor. The ceiling of the 1st floor unit under the Chan is lowest around $1.3 \sim 1.5 \mathrm{~m}$ and that of under the house unit is $1.6 \mathrm{~m}$ (Fig.5 section). Residents use this lower ceiling as sleeping space. Four units out of 8 house units on the 1st floor extended their living space with a higher ceiling and used it for daily activities such as eating, relaxing and communicating with people (X1,X5, X10 and X14). There are 9 cases of Type 3 having exclusive sleeping space with doors. These exclusive sleeping spaces are seen at larger units.

In this regard, respective of the size of the floor area of the unit, the organization of space followed the space pattern. Exclusive sleeping space with doors can be seen in larger house units. However even smaller house units tend to separate sleeping space from other activities by placing furniture, partitions, floor mats or floor levels. It was common to differentiate between space for sleeping and space for communicating, eating and relaxing. This organization of house unit space can be seen in Fig.6.

\section{3-5 Multipurpose Connecting Space CER}

There is not clear demarcation among space for eating, relaxing and communicating with people. There are several reasons behind this phenomena. One reason is insufficient floor area. However use of space does not much differ in larger units. Residents' living style is thought to be more important. Living space extends to outdoor space and does not require any specific furniture for eating or relaxing. Thai houses are often seen having one large room for multipurpose activities including eating, relaxing, communicating with people ${ }^{16}$.

Since this space is thought to be one space, expressed

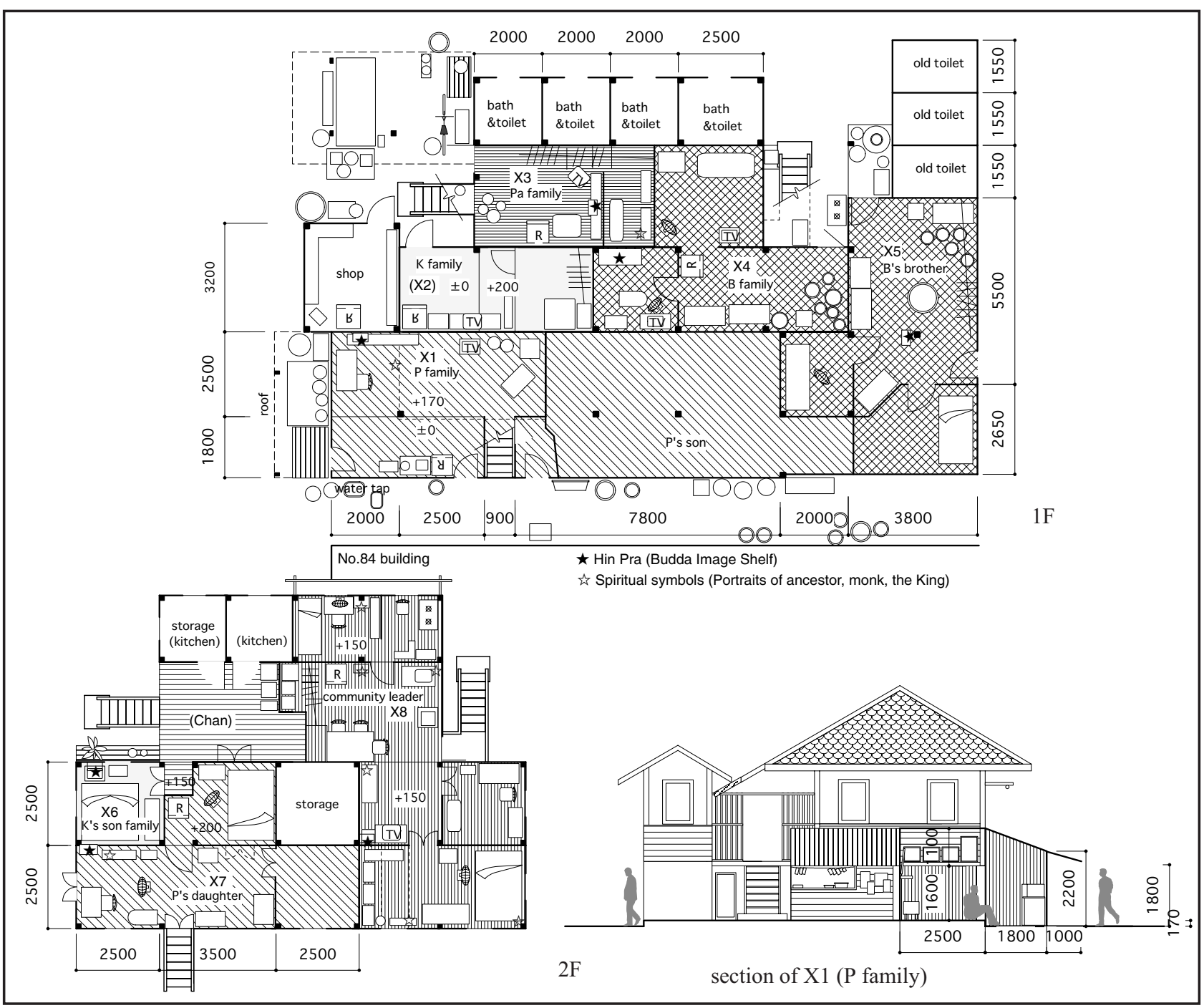

Fig. 5. RH6 No. 88 Building (the only one case shared Chan has been modified) 
as CER hereafter ( $\mathrm{C}$ : communicating with people, E: eating and R: relaxing). CER is used for multipurpose activities including watching TV, reading, playing, taking a nap, and for exhibition of decoration or spiritual symbols. The floor level differs in this CER and visitors sit down on the step and talk with residents. Similar arrangement are seen in regional Thai houses ${ }^{17}$. The role of CER as a space for connecting the outside with the inside is more clearly understood by the steps in this case. This space also connects rooms at lager house units.

There are similar interior arrangements of the space for CER. It contained symbolic arrangement such as Hin
$\mathrm{Pra}^{18}$ (Budda Image shelf) or portraits of the King or ancestor. More than two thirds of the house units have Hin Pra in the CER. House units on the 1st floor put the roof just below the windows on the 2 nd floor. The portraits of deceased, higher ranked monk or the King are hung on the walls under the windows (X1,X3,X10, X14 Fig. 5 section and Fig. 7-1). People visiting the house unit see these arrangements and understand what residents are. This space has symbolic and social meanings.

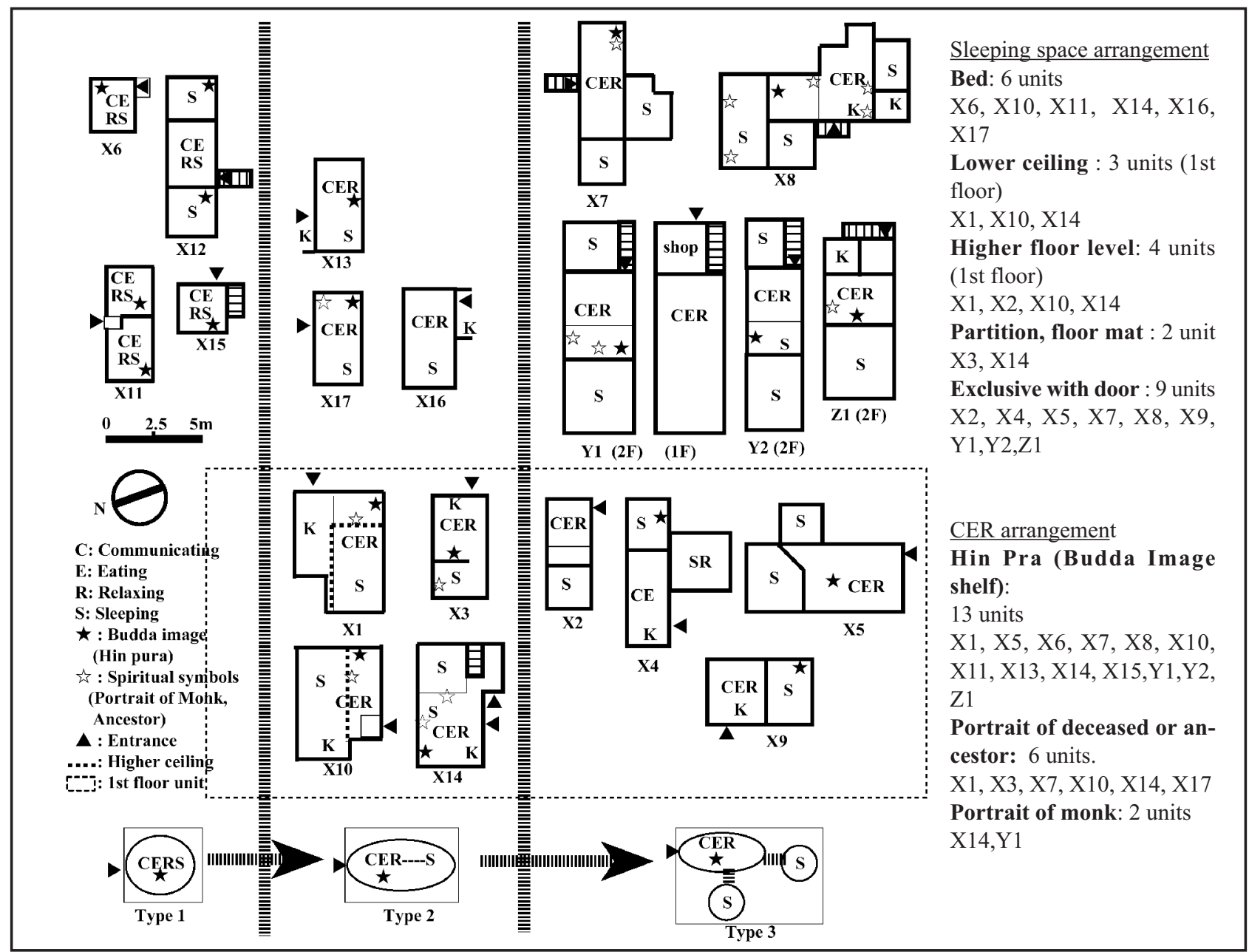

Fig. 6. Saptial Characteristics of House Unit

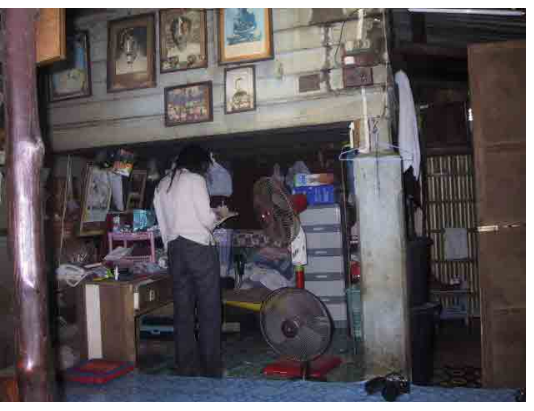

1. Portraits of ancestor on the wall under the windows

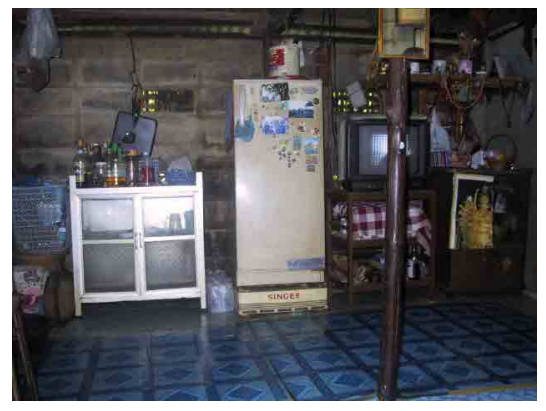

2. Looking at kitchen space. Hinpra is upper right corner.

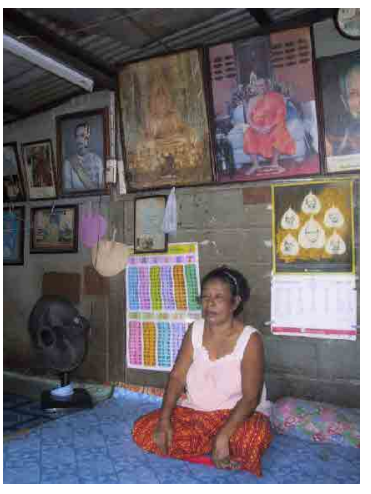

3. Portraits of the Monk. Different pattern of floor mat is sheeted at the sleeping space.

Fig. 7. Interior of the House Unit X14 


\section{3-6 Relations Between Shared Chan and House Units}

There are different spatial characteristics between units on the 1st floor and those of the 2nd floor. Residents on the 1st floor tend to have CER space and demarcate CER from sleeping space with some arrangements. Units on the 2nd floor on the other hand, do not have such clear demarcation (Fig.6 Type 1 and Type 2). This is partly because of the physical restrictions caused by insufficient floor area. However it can be assumed that units on the 2nd floor are relieved of the stress of having CER since they connect with the shared Chan. The different use of house units implies that the residents can recognize the Chan or the Chalieng space on the 2 nd floor as CER space. This is shown in the diagram in Fig.8.

At the beginning the open Chan of the row houses were designed to fit the natural and social environments. The Chan was designed to accommodate living activities and as circulation space. The Chan in the RH6 is not comfortable or actively used for communication as it used to be because the extension of underneath prevents ventilation and disorder come from increasing number of commodity placed on it. The Chan, however, has undergone minor modifications. It is still used to support their lives as working space, housework space, storage, passage and ritual space. In addition, the spatial perception of Chan as multipurpose connecting space is still shared among residents and helps collective living. This shows the importance of the shared Chan in urban housing planning.

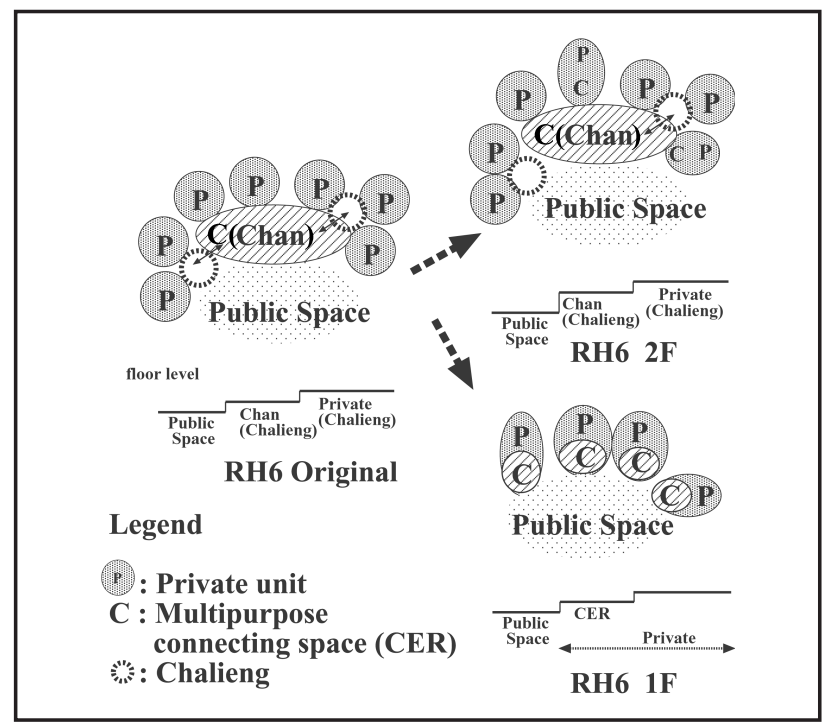

Fig. 8. Spatial Composition of the House Unit with Shared Chan

\section{Conclusion}

This study has explored the use of Chitlada SRT housing units and has reached the following conclusions: 1) The house unit at RH6 varies, although it was originally planned from 6.25 to 12.5 square meters. The organization of space followed the space pattern. Exclusive sleeping space with doors can be seen in larger house units. However even smaller house units tend to have demarcation between space for sleeping and that of other activities by placing furniture, partitions, floor mats or floor levels. It was common to differentiate between space for sleeping and space for communicating, eating and relaxing.

2) There is not clear demarcation among space for eating, relaxing and communicating with people. This space serves lots of activities and expressed as CER in this paper. The spatial characteristics of CER stands for space for communicating with people, connecting space, eating, expressions of resident's identities and relaxing. This space has symbolic and social meanings.

3) The Spatial characteristics between the units on the 1st floor and those of the 2nd floor are slightly different. Residents on the 1st floor tend to have CER and demarcate CER from sleeping space with some arrangements. However house units on the 2nd floor do not strongly demarcate these space. The use of house units implies that the Chan or the Chalieng space on the 2nd floor can be recognized as CER space.

4) The original Chan in the RH6 was a semi-outdoor space and shared with residents to fit the natural and social environments. It is not comfortable or actively used for communication as it used to be because the extension of underneath prevents ventilation and has become cluttered with objects used in daily life. The Chan, however, is still used to support residents' practical necessities as working space, housework space, storage, passage and for ceremonies such as inviting monks to bring happiness or funeral ceremonies. Furthermore the spatial perception of Chan as a multipurpose connecting space is still shared among residents and helped collective living.

5) It is 60 years ago that the Chitlada SRT housing site was built. Row houses with shared Chan and the Chalieng have been kept with minor modifications. Residents extended their living space inside and outside the building according to their needs. This house unit planning with shared Chan and the Chalieng has brought variety of space utilization and has contributed to a way of life for the residents. The analyses indicate the importance of the shared Chan in the planning.

\section{Acknowledgments}

The author express her appreciation to Dr. Yongtanit Pimonsathean and Mr. Jaturong Pokharatsiri at KMITL for providing information and assisting. Appreciation is extended to Professor Onsiri Panin and Professor Vira Inpuntung at Silpakorn University for useful discussion. This research was supported in part by Jutaku Sougou Kenkyu Zaidan and JSPS.

\section{Notes}

1. The SRT housing was developed at almost the same time as the commencement of the railway services in Thailand in 1896 (Reference 4, p.2). Reference 5 mentioned that SRT was the largest government organization with more than 15,000 employees in 1930s. The SRT housing can be said as the earliest welfare housing from these references. Reference 8 outlined the existing urban housing types at all income levels in Bangkok. The SRT housing is placed on one out of 16 housing types. 
2. Reference 9 explained detail of living conditions. The SRT housing is a kind of welfare, residents do not have to pay for house. They have individual meters for electricity and water supply since 1982. The average size of household is 4.6 person per household. The average period of stay in the SRT house is 17.7 years while the longest stay is more than 40 years. Social interaction is solid. The average household income of row house is $23,915 \mathrm{baht} / \mathrm{month}$, which is slightly less than that of Bangkok region (26,571 baht/month). Only $31 \%$ have already prepared their houses after retirement.

3. Reference 5

4. Reference 2

5. Reference 4

6. Reference 9

7. Reference 10

8. RH1, RH2, RH4 and RH6 exist in Chitlada. House unit of each type were measured (X1 17, Y1,2 and Z1 in Table1). Interviewed household were RH1 (No.24, 28), RH2 (No.142), RH4 (78/2), RH6 (No.80, $88,92,98,102)$, and New row house (No.90).

9. Focusing RH6 but including RH1, RH2 and RH4 for references.

10. Reference 9

11. The community leader at No.88 made partition by walls on shared Chan. Reference 9.

12. There is not clear definition of Chalieng. Professor Onsiri Panin at Silpakorn University explained 'Chalieng' as part of house (Ruen) next to the room or corridor and suggested to use 'veranda' in English. Professor Vira Inpuntung at Silpakorn University also explained that Chalieng could be accessed from the public space. They explained 'Chan' as connecting space and suggested to use 'terrace' in English. (by interview :July 2001).

13. The reason of conversion to the rental room is thought to that units connecting the Chalieng B are only two and isolated with exclusive access staircases.

14. Professor Onsiri Panin and Professor Vira Inpuntung at Silpakorn University explained the difference between 'Chalieng' and 'Rabiang' are vague. They explained Rabiang is also expressed as 'veranda' in English. Residents distinguished Chan and Rabiang. It seemed that Rabiang is recognized more closed private small space than Chan by the residents. However, further research is necessary in this term concept.

15. Residents can receive two units if they request since 1980s. Reference 9.

16. Reference 6,7 .

17. Reference 1,7

18. Most of Thai Buddhist equip Hin Pra. People offer incense sticks, water and flowers to the Budda image in general.

\section{References}

1) Chaichonrak Ruthai (1977) Ruan Thai Deem, Silpakorn University.

2) Kakizaki Ichiro (2000) Tai keizai to tetsudo 1885-1935, nihonkeizaihyouronsha.

3) Mom Chao Vodhyakara Foundation (1991) Works of Mom Chao Vodhyakara Varavarn 1900-1981.

4) Pimonsathean Yongtanit, Chukaew Parinya Tirawipas Kringsak, Mitinunvong Chatchai and Charoenkoopta Panpong (2000) The Study of State Railway of Thailand (SRT) Welfare Housing in Bangkok, King Mongkut's Institute of Technology Ladkrabang, unpublished report.

5) Suehiro Akira (1996) 'Senzenki Thai tetsudou no hattenn to gizyutsusyakeisei’ Sougouteki Chiiki Kenkyu No.15.

6) Tanaka Mari, Akazawa Akira, Funo Shuji and Kobayashi Masami (1998) Transitional Process of the Corehouses at Tung Song Hong Planned Settlement in Bangkok, J. Arch. Plann. Environ. Eng., AIJ, No.512, 93-99.

7) Tanaka Mari (2001) The Regional Characteristics of the Rural Houses in Thailand, Annual Reports of the Faculty of Education Gunma University, No.36, pp.219-240.

8) Tanaka Mari and Funo Shuji (2001) Urban Housing Types Based on Housing Supply in Bangkok, J. Arch. Plann. Environ. Eng., AIJ, No.548, 237-242.
9) Tanaka Mari, Kikuchi Yukiyo and Funo Shuji (2002) Transition of Row Houses at Chitlada State Railway of Thailand Housing Site in Bangkok- Multipurpose Space such as Thaithun (underneath) and Chan (terrace) -, J. Of Asian Architecture and Building Engineering, AIJ, AIK, ASC, Vol.1, No.1, pp.271-279.

10) Yamamoto Naohiko, Tanaka Mari, Wakita Yoshihisa and Funo Shuji (1997) Utilization of Common Space in Rumah Susun Sombo (Surabaya, Indonesia), J. Arch. Plann. Environ. Eng., AIJ, No.502, 87-93. 